\title{
Menstrual pattern and menstrual disorders among adolescents: an update of the Italian data
}

Franco Rigon ${ }^{1}$, Vincenzo De Sanctis², Sergio Bernasconi ${ }^{3}$, Luigi Bianchin ${ }^{4}$, Gianni Bona ${ }^{5}$, Mauro Bozzola ${ }^{6}$, Fabio Buzi ${ }^{7}$, Giorgio Radetti ${ }^{8}$, Luciano Tato ${ }^{9}$, Giorgio Tonini ${ }^{10}$, Carlo De Sanctis ${ }^{11}$ and Egle Perissinotto ${ }^{12^{*}}$

\begin{abstract}
Background: The most striking event in the whole process of female puberty is the onset of menstruation. To our knowledge, no large population-based studies have been performed on the topic of menstrual health among Italian adolescents in recent years.

The aims of this study were to produce up-to-date information on the menstrual pattern of Italian girls attending secondary school, and to estimate the prevalence of menstrual cycle abnormalities in this population.

Methods: This was a cross-sectional study on a population-based sample of Italian adolescents aged 13-21 years attending secondary school. Only girls who had already started menstruating were requested to participate. Information was collected by means of a questionnaire that included items on the girls' demographic details, anthropometrics, smoking and drinking habits, use of contraceptive pills, and socioeconomic status. The questions on the girls' menstrual pattern concerned their age at menarche, duration of the most recent menstruation intervals ( $<21,21-35,>35$ days, variable), average days of bleeding $(<4,4-6,>6$ days), and any menstrual problems and their frequency.
\end{abstract}

Results: A total of 6,924 questionnaires were administered and 4,992 (71\%) were returned. One hundred girls failed to report their date of birth, so 4,892 subjects were analyzed. The girls' mean age was 17.1 years (SD \pm 1.4 ); their mean age at menarche was $12.4( \pm 1.3)$ years, median 12.4 years $(95 \% \mathrm{Cl} 12.3-12.5)$.

In our sample population, 3.0\% (95\% $2.5 \%-3.4 \%)$ of the girls had menstruation intervals of less than 21 days, while it was more than 35 days in $3.4 \%(95 \% \mathrm{Cl} 2.9 \%-3.9 \%)$. About $9 \%$ of the girls $(95 \% \mathrm{Cl} 7.7 \%-9.4 \%)$ said the length of their menstruation interval was currently irregular. Short bleeding periods ( $<4$ days) were reported in $3.2 \%$ of the sample population (95\%Cl 2.7\%-3.7\%), long periods (>6 days) in 19\% (95\%Cl 17.9\%-20.1\%). Menstruation-related abdominal pain was reported by about $56 \%$ of our sample. About $6.2 \%$ of the girls ( $95 \% \mathrm{Cl} 5.4 \%-7.0 \%$ ) were suffering from dysmenorrhea.

Conclusions: In conclusion, to the best of our knowledge, this is one of the largest studies on menstrual patterns and menstrual disorders among Italian adolescent girls. Adolescent girls referring persistent oligomenorrhoea, in first two years from menarche, had a higher risk for developing a persistent menstrual irregularity. They had longer bleeding periods ( $>6$ days) and this has practical implications because it makes these adolescents potentially more susceptible to iron deficiency anemia. Clinicians need to identify menstrual abnormalities as early as possible in order to minimize their possible consequences and sequelae, and to promote proper health information. We recommend that adolescents should be encouraged to chart their menstrual frequency and regularity prospectively from the menarche onwards.

Keywords: Menstrual pattern, Menstrual disorders, Menstrual cycle length, Bleeding length, Polymenorrhea, Oligomenorrhea, Dysmenorrhea, Adolescents

\footnotetext{
* Correspondence: egle.perissinotto@unipd.it

${ }^{12}$ Department of Cardiac, Thoracic and Vascular Sciences, University of Padua, Padua, Italy

Full list of author information is available at the end of the article
}

\section{Biomed Central}

(C) 2012 Rigon et al.; licensee BioMed Central Ltd. This is an Open Access article distributed under the terms of the Creative Commons Attribution License (http://creativecommons.org/licenses/by/2.0), which permits unrestricted use, distribution, and reproduction in any medium, provided the original work is properly cited. 


\section{Introduction}

Adolescence is the time of life between puberty and psychophysical maturity when crucial endocrinological, metabolic, somatic and psychological changes occur in girls. During this process, sequential phases mark the maturation of the complex endocrinological system that comprises the hypothalamus, pituitary gland, and ovary, and their interactions. Healthy reproductive function is the expected endpoint of this process [1-3].

The timing of this process is individual-specific, within a broad range of normality. The most frequent menstrual disorders are polymenorrhea, oligomenorrhea and dysmenorrhea [4-7]. Menstrual abnormalities are more common among younger girls, becoming less frequent as they grow older, 3-5 years after menarche [8-12]. Clinical evidence from the literature indicates that as of the third year after menarche the interval between bleeding periods is in the range of 21-34 days, with a flow lasting from 3 to 7 days and a mean menstrual blood loss of $35 \mathrm{ml}$ (range 5-80 ml) [4-6]. Frequent anomalies outside normal references occasionally occur, or may become chronic, suggesting a shift from the normal endocrine-gynecological functional axis. Occasional deviations usually have temporary causes, such as psychological or physical stress, while chronic anomalies are much more likely to have pathological organic causes such as polycystic ovary, endometriosis, hypogonadism or cancer.

Population-specific reference data are useful to establish what is normal and acceptable, and what is not. Few population studies have been conducted in Italy on normal and dysfunctional characteristics of menstrual cycles. Since a knowledge of their variability is needed for patient education purposes and to guide clinicians' investigations, treatment and follow-up, a cross-sectional school survey was conducted in 16 Italian cities (all over the country).

\section{Methods}

\section{Sample and questionnaire}

This was a cross-sectional study on a population-based sample of Italian adolescents aged 13-21 years attending secondary school. Information was collected by means of a questionnaire. A list of secondary schools was randomly selected in 16 Italian cities located all over the country (Brescia, Bolzano, Ferrara, Foggia, Lecce, Modena, Novara, Padova, Parma, Pavia, Reggio Emilia, Taranto, Torino, Trieste, Verona, Vicenza). All the schools agreed to take part in the study and a local investigator explained the aims of the survey and the questionnaire to the science teachers at each school, who relayed this information to their students and distributed the questionnaires. Only girls who had already started menstruating were requested to participate. Informed written consent was obtained from the students and their parents/guardians.

The girls were asked to complete an anonymous, selfadministered questionnaire. Details on the sampling strategy used and on the questionnaire have been described in a previous publication [12].

The questionnaire included items on the girls' demographic details, anthropometrics (weight, height), smoking and drinking habits (yes/no; frequency), use of contraceptive pills and reasons for their use (as a contraceptive, to regularize their menstrual cycle, or both), and socioeconomic status (Hollingshead index [13], where socioeconomic status is scored from 0 for the lowest social level to 14 for the highest).

The girls were asked to indicate their birth date (day, month, year) and, as accurately as possible, the date of their first menstrual bleeding (at least the month and the year); when the day was missing, the event was considered as it was happened at half month.

Age at interview was obtained as difference between interview and birth date divided by 365.25 . Menarcheal age was computed as difference between birth and menarcheal date divided by 365.25. Age at interview and age at menarche were expressed as decimal year.

The questions on the girls' menstrual pattern concerned their age at menarche, duration of the most recent menstruation intervals $(<21,21-35,>35$ days, variable), average days of bleeding $(<4,4-6,>6$ days), and any menstrual problems and their frequency. The impact of the menstrual cycle on the girls' physical and psychological complaints was also investigated.

The following definitions were used to describe menstrual cycle disorders: polymenorrhea was defined as a menstruation interval lasting less than 21 days; oligomenorrhea as a menstruation interval of more than 35 days [14,15]; dysmenorrhea as abdominal pain severe enough to interfere with normal activities, or require medication. Abdominal pain was ranked on four levels (the last of which was termed as dysmenorrhea), as follows: no or mild/moderate abdominal pain; severe abdominal pain without any use of drugs, or sufficient to limit the girl's activities; severe abdominal pain treated with drugs, and/or activity limitations during bleeding days; or severe abdominal pain treated with drugs and/or activity limitations before bleeding days $[16,17]$.

\section{Statistical analysis}

Descriptive statistics were obtained to describe the study population as a whole and divided into subgroups. Mean values and standard deviations (SD) were calculated for quantitative variables; median, first and third quartile were evaluated for age at menarche. Frequency distributions were calculated for qualitative variables. The prevalence of polymenorrhea, oligomenorrhea and dysmenorrhea was 
estimated with $95 \%$ confidence intervals $(95 \% \mathrm{CI})$. Differences in proportions were analyzed using the chi square test or Fisher's exact test, as appropriate. The chi square test for trend was used to assess the role of ordinal variables. Parametric and non-parametric one-way analyses of variance (ANOVA) were used to check differences between mean values of quantitative variables.

The linear trends of mean values for quantitative variables were estimated by applying simple linear regression models.

All statistical analyses were performed using SAS statistical software, rel. 9.1 (SAS Institute, Cary, NC, USA). The significance level was set at 0.05 and all tests were two-tailed.

\section{Results}

A total of 6,924 questionnaires were administered and 4,992 (71\%) were returned. The sample population only included Caucasian girls. One hundred girls failed to report their date of birth, so 4,892 subjects were analyzed. Only for analyses regarding the date at menarche the sample population sized at 3,783 (77\%) with complete information.

The girls were a mean 17.1 years of age $(\mathrm{SD} \pm 1.4)$; their mean age at menarche was $12.4( \pm 1.3)$ years, median 12.4 years (first quartile 11.5 years; third quartile 13.2 years). They generally belonged to middle- to highclass families, with only $9 \%$ of them scoring lower than 7 on the social scale.

Table 1 shows the general characteristics and the age at menarche for the sample as a whole and for the various age groups. Anthropometric and lifestyle changes emerged with age, including a significant increase in the numbers of smokers (from $19 \%$ to $42 \%$; $<<0.0001$ ), drinkers (from $38 \%$ to $56 \%$; $<0.0001$ ) and contraceptive pill users (from 2\% to 25\%; $\mathrm{p}<0.0001$ ) among the older groups, and a decrease in the prevalence of physical activity (from $58 \%$ to $39 \% ; \mathrm{p}<0.0001$ ). It is worth noting that the rising trend seen in the age of menarche with increasing age at the time of answering the questionnaire (from 12.1 to 12.6 years) was due to the study design. Given that only girls who had already their first menses were included, the older groups - unlike the youngest girls - also included girls who had experienced their menarche when more than 14 years old (the age at which they started secondary school). In line with the well-known association between a girl's and her mother's age at menarche, our findings confirmed the recognized tendency for girls to be younger at menarche than their mothers [12].

The following data describing the features of our sample's menstrual pattern were obtained.

In our sample population, $3.0 \%$ (95\%CI $2.5 \%-3.4 \%$ ) of the girls had menstruation intervals of less than 21 days, while it was more than 35 days in 3.4\% (95\% CI $2.9 \%-3.9 \%$ ). About $9 \%$ of the girls $(95 \% \mathrm{CI} 7.7 \%$ 9.4\%) said the length of their menstruation interval was currently irregular, whereas about $72 \%$ reported it having done so in the past. Short bleeding periods ( $<4$ days) were reported in $3.2 \%$ of the sample population (95\% CI $2.7 \%-3.7 \%)$, long periods ( $>6$ days) in $19 \%$ (95\%CI 17.9\%-20.1\%).

When asked about any previous experience of polymenorrhea or oligomenorrhea, these conditions were reported by $34 \%$ and $51 \%$ of the girls, respectively.

Figures 1 and 2 show the menstruation intervals and bleeding periods by age at interview: the proportion of girls with a regular cycle rose constantly from $81 \%$ at 14 years of age to $87 \%$ at 20 years old $(\mathrm{p}=0.0002)$, while

Table 1 General characteristics of a population-based sample of Italian secondary school girls

\begin{tabular}{|c|c|c|c|c|c|c|c|c|c|}
\hline & \multirow[b]{2}{*}{ Whole sample } & \multicolumn{8}{|c|}{ Age at data collection } \\
\hline & & $<=14$ years & 15 & 16 & 17 & 18 & 19 & $>=20$ & $p$ for trend \\
\hline$n$ & 4892 & 301 & 501 & 1335 & 1433 & 952 & 258 & 107 & \\
\hline Weight (kg) & $55.5 \pm 7.6$ & $53.3 \pm 8.1$ & $54.5 \pm 7.8$ & $55.4 \pm 7.0$ & $55.5 \pm 7.6$ & $55.7 \pm 7.6$ & $56.7 \pm 8.3$ & $56.8 \pm 8.9$ & $<0.0001$ \\
\hline Height (cm) & $165.5 \pm 6.1$ & $163.4 \pm 5.8$ & $165.1 \pm 6.1$ & $165.7 \pm 5.9$ & $165.6 \pm 6.2$ & $165.9 \pm 6.1$ & $165.8 \pm 6.5$ & $164.7 \pm 6.7$ & $<0.0001$ \\
\hline $\mathrm{BMI}\left(\mathrm{kg} / \mathrm{m}^{3}\right)$ & $20.3 \pm 2.5$ & $20.0 \pm 2.7$ & $20.4 \pm 2.6$ & $20.2 \pm 2.3$ & $20.3 \pm 2.5$ & $20.2 \pm 2.4$ & $20.7 \pm 2.8$ & $21.0 \pm 2.9$ & 0.01 \\
\hline Family size $\left(n^{\circ}\right)$ & $2.0 \pm 0.7$ & $1.9 \pm 0.7$ & $2.1 \pm 0.7$ & $1.9 \pm 0.7$ & $1.9 \pm 0.7$ & $1.9 \pm 0.7$ & $2.0 \pm 0.7$ & $2.0 \pm 0.7$ & 0.12 \\
\hline Smoking habit (\%) & 32.6 & 19.3 & 26.8 & 26.7 & 35.8 & 39.3 & 43.8 & 42.1 & $<0.0001$ \\
\hline Alcohol drinking (\%) & 55.0 & 38.2 & 46.1 & 51.2 & 59.3 & 62.7 & 58.5 & 56.1 & $<0.0001$ \\
\hline Physical activity (\%) & 50.0 & 57.8 & 57.9 & 56.2 & 50.0 & 39.4 & 36.8 & 39.3 & $<0.0001$ \\
\hline Previously on pill (\%) & 22.0 & 12.3 & 21.4 & 15.3 & 21.8 & 28.6 & 38.8 & 40.2 & $<0.0001$ \\
\hline Currently on pill (\%) & 12.6 & 2.3 & 5.6 & 7.6 & 12.9 & 20.2 & 29.1 & 25.2 & $<0.0001$ \\
\hline for contraception (\%) & 8.7 & 1.0 & 3.6 & 4.9 & 9.0 & 13.5 & 21.7 & 21.5 & $<0.0001$ \\
\hline for cycle regularity (\%) & 4.8 & 1.3 & 2.4 & 2.8 & 5.3 & 7.7 & 10.5 & 5.6 & $<0.0001$ \\
\hline Age at menarche (years) & $12.4 \pm 1.3$ & $12.1 \pm 1.1$ & $12.3 \pm 1.3$ & $12.3 \pm 1.2$ & $12.5 \pm 1.3$ & $12.5 \pm 1.3$ & $12.6 \pm 1.5$ & $12.6 \pm 1.6$ & $<0.0001$ \\
\hline Mother's age at menarche (years) & $12.7 \pm 1.6$ & $12.6 \pm 1.5$ & $12.8 \pm 1.7$ & $12.6 \pm 1.5$ & $12.7 \pm 1.6$ & $12.8 \pm 1.6$ & $12.8 \pm 1.8$ & $12.9 \pm 1.6$ & 0.07 \\
\hline
\end{tabular}




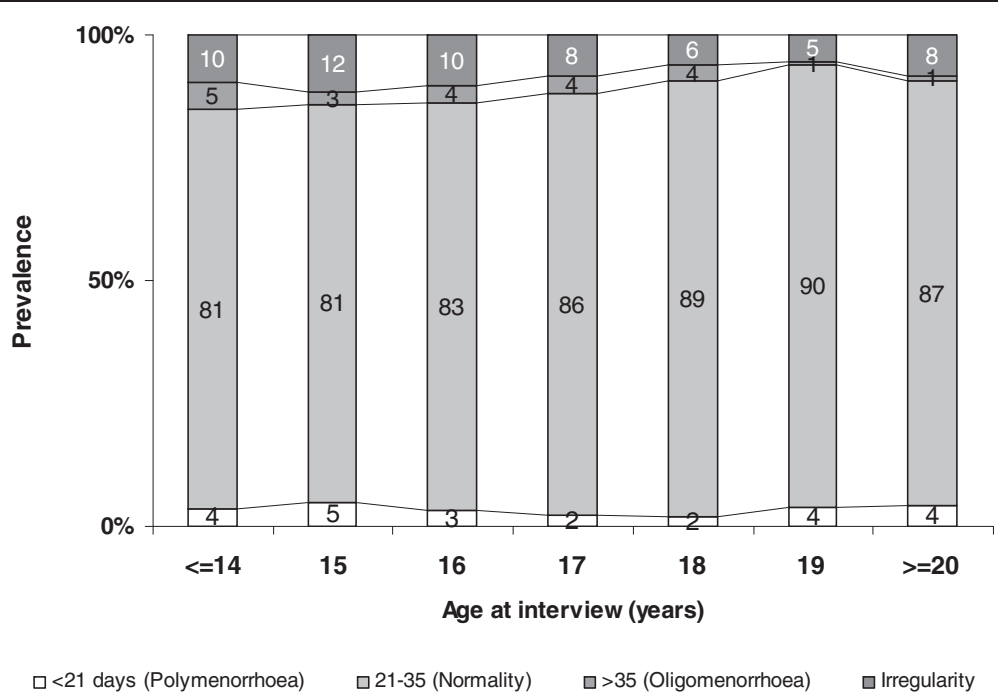

Figure 1 Distribution of duration of menstruation interval by age at data collection $(p=0.0002)$.

the prevalence of long bleeding periods ( $>6$ days) dropped from $22 \%$ to about $13 \%$ ( $\mathrm{p}$ for trend $=0.009$ ).

Figure 3 shows the association between menstruation interval and bleeding period $(\mathrm{p}<0.0001)$. Oligomenorrhea was related to longer bleeding periods (32\%) and also a variable menstruation interval (31\%).

As shown in Figure 4, our results indicate that menstruation interval was significantly more regular among girls using the pill $(\mathrm{p}<0.0001)$.

Menstruation-related severe abdominal pain was reported by about $56 \%$ of our sample. Among those girls, $42 \%$ took pain medication and $11 \%$ of them experienced limitations in their normal activities. Among girls with severe pain, $10 \%$ satisfied the criteria for dysmenorrhea, while referring to the whole sample population the prevalence of dysmenorrhea was 6.2\% (95\%CI 5.4\%-7.0\%).

In the whole sample, the prevalence of dysmenorrhea (Figure 5) significantly increased with age, rising from about $2 \%$ in the youngest age group age to about $8 \%$ among the over 17 year-olds. It was not significantly associated with the length of the menstruation interval, but there was clearly a significant association with the length of the bleeding period, the prevalence being about $7 \%$ among subjects with bleeding periods $<4$ days or $>6$ days, as opposed to about $5 \%$ for those with periods lasting 4-6 days $(\mathrm{p}=0.01)$.

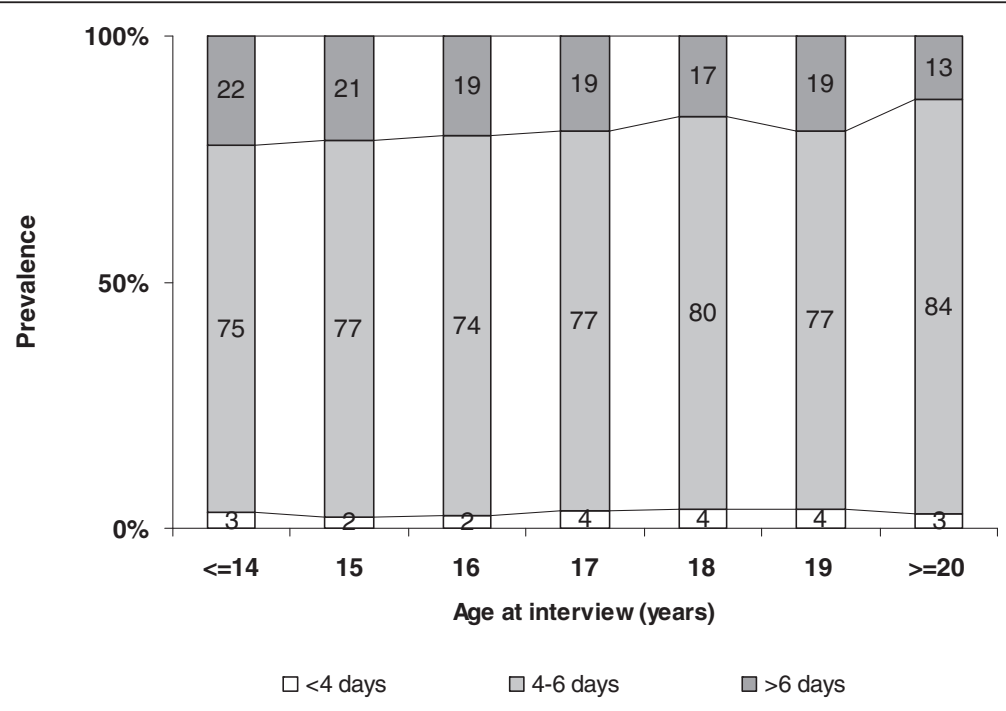

Figure 2 Distribution of duration of bleeding period by age at data collection (prevalence of $>6$ days, $p$ for trend 0.008 ). 


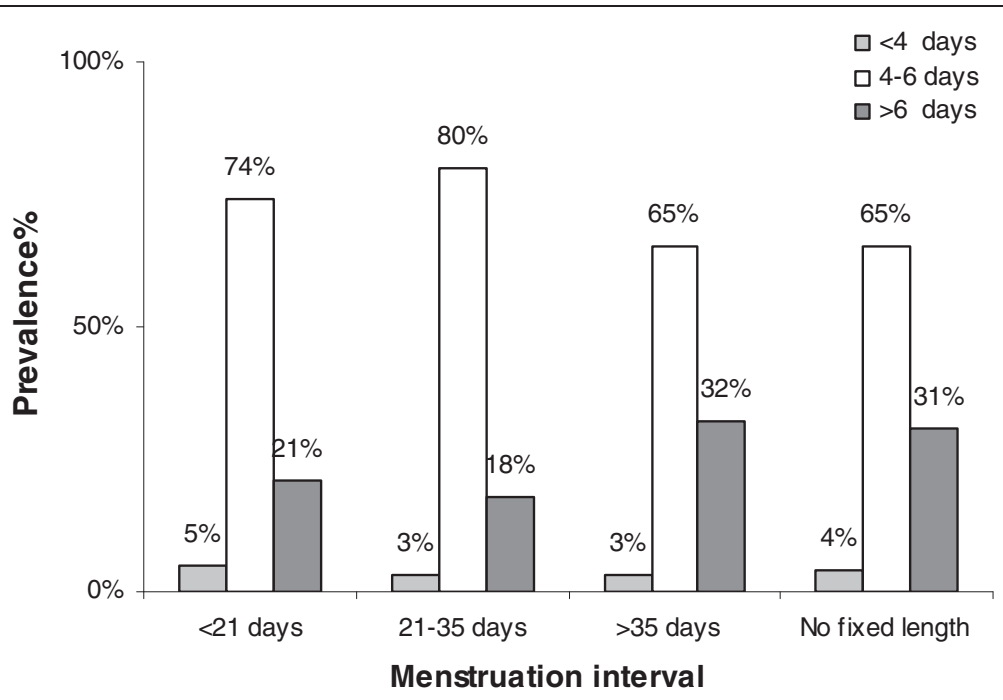

Figure 3 Distribution of length of bleeding period by length of menstruation interval $(p<0.0001)$.

\section{Discussion}

The most striking event in the whole process of female puberty is the onset of menstruation.

The average age of menarche in Western European countries appears to have dropped over the past 150 years from over 16 to under 14 years old [18]. In Italy, the mean age at menarche was estimated at $12.4 \pm 1.3$ years $[12,19]$.The declining age of puberty has been attributed to better living standards, e.g. adequate nutrition and health care $[7,12]$.

The onset of menarche does not mean that the pituitary-gonadal axis (H-P-G) is fully developed and capable of regular function [20,21].

Although menstrual irregularities in adolescent girls are often attributed to an immature H-P-G axis [22], many adolescents with persistent menstrual abnormalities may raise concern of polycystic ovarian syndrome (PCOS) $[8,9,23]$. PCOS affects about $5 \%$ to $10 \%$ of women $[24,25]$ in their reproductive life and can be associated with reproductive disorders, cardiovascular disease, type II diabetes mellitus and metabolic syndrome [26-28]. Because the clinical presentation of PCOS varies, it is important to have specific diagnostic criteria. In 2003, the ESHRE/ASRM Consensus introduced new phenotypes of PCOS requiring two of the following diagnoses of PCOS: chronic anovulation, biochemical and or clinical hyperandrogenemia and distinct sonographic appearance of ovaries [29]. The clinical significance of these phenotypes is controversial and the Androgen Excess Society position statement did not declare the inclusion of

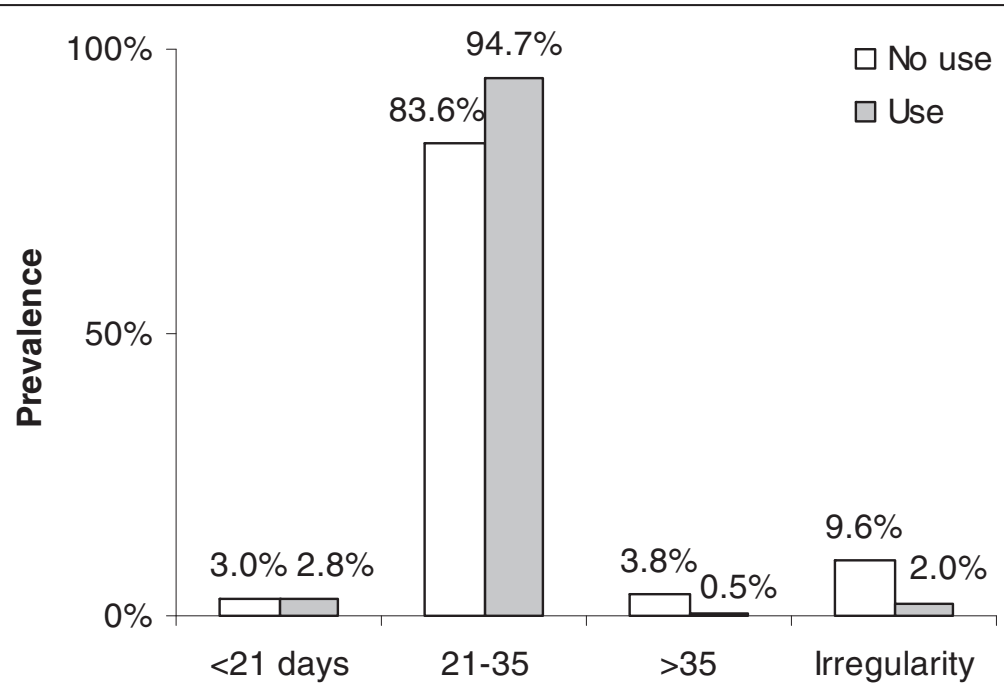

Figure 4 Distribution of length of menstruation interval by use of contraceptive pill $(p=<0.0001)$. 


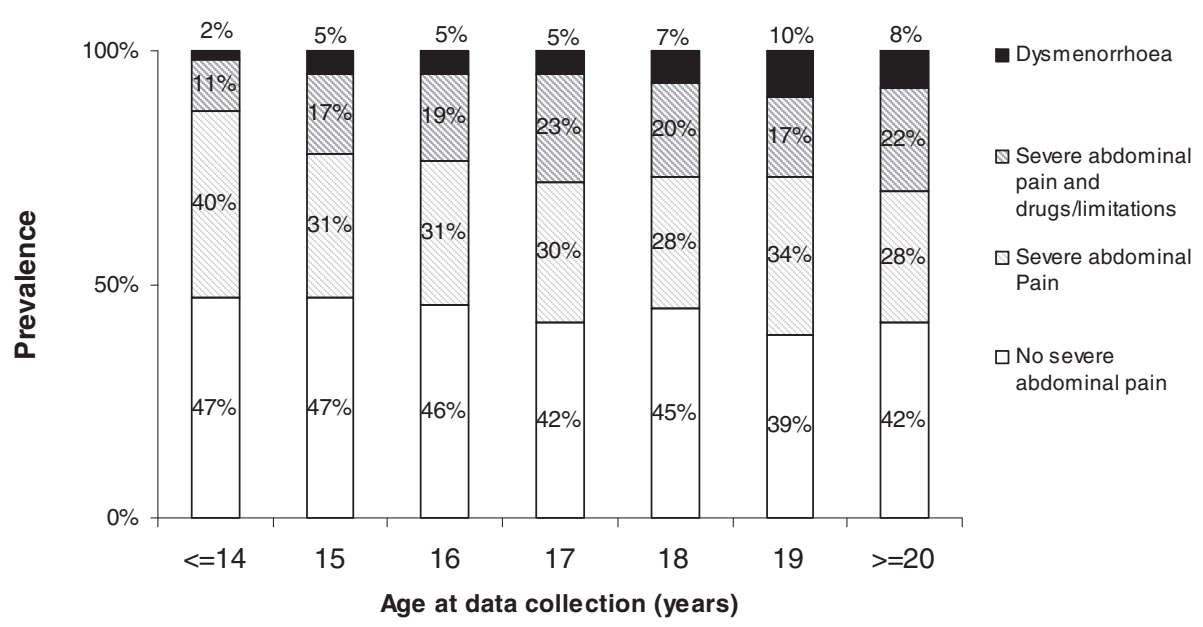

Figure 5 Prevalence of severe abdominal pain, from none to dysmenorrhea, by age at data collection ( $p$ for trend $<0.0001$ ).

anovulatory non-hyperandrogenic women with ultrasonographic polycystic ovarian morphology in the PCOS cohort [30].

The schoolgirls included in our study had their first menstrual period at approximately the same age as their mothers, though there was a tendency for girls to be younger at menarche than their mothers. Similar results have been reported by Russo et. al [19] in a large population of Italian adolescents. The mean time lapse from B2 to B3 and B2 to menarche was 1.4 and 2.7 years, respectively [19]. These data further support for a genetic effect on age at menarche $[1,2,12]$,

BMI, family size and birth order are other factors believed to influence age at menarche [31-34]. Although Gallo [33] found a mean age at menarche of 12.8 years for girls born in Northern Italy from large families as opposed to 12.6 for those from small families and Malina et al. [34] also reported a significant correlation between the age at menarche, family size and birth order, in our study the effect of family size was irrelevant.

By the mean age of 17.1 years, 3\% of the subjects had cycles shorter than 21 days and in 3.4\% they were longer than 35 days. A shorter than normal bleeding period ( $<4$ days) was reported by $3.2 \%$ of our sample population, and a long bleeding period ( $>6$ days) by $19 \%$ of the girls.

Dewhurst et al. [35] analyzed 368 menstrual periods and found that the flow lasted between 3 and 7 days in $88 \%$ of the cycles, with an average length of 5 days. In a larger series described by Widholm and Kantero [36], short periods of 2-3 days occurred in $8.8 \%$ of the girls during the first menstrual year, but this figure dropped to $3.7 \%$ by the fifth year.

It is important to remember that prolonged menstruation intervals and heavy menstrual bleeding warrant attention when these conditions are associated with anovulation or oligo-ovulation, hirsutism or moderatesevere acne [37-39]. Polycystic ovary syndrome (PCOS), Cushing's disease, thyroid dysfunctions, premature ovarian failure, strong physical exercise, eating disorders, congenital adrenal hyperplasia, ovarian and adrenal tumors or prolactinomas are all examples of endocrine dysfunctions that can cause oligomenorrhea. Although some of these conditions are rare, others are more common and warrant careful evaluation and management, especially in cases with signs of androgen excess, irrespective of the subject's menstrual or gynecological age $[5,11,23,37,38]$.

Studies on female teenagers with heavy bleeding or hemorrhage have also identified coagulopathies in up to $20 \%$ of cases, the most common being von Willebrand disease, which occurs in as many as $15 \%$ of women $[40,41]$.

The challenge for the physician is to distinguish between bleeding abnormalities secondary to anovulation and disorders requiring further investigation and a specific follow-up, as well as screening adolescents at risk for iron deficiencies [42-44].

Menstruation may be associated with various symptoms occurring before or during menstrual flow. A significant number of our students complained of dysmenorrhea, and this was more common among older girls with longer bleeding periods $(16.7 \%$ among those whose bleeding period lasted $<4$ days, $24.1 \%$ for periods lasting 4-6 days, and $37.2 \%$ for periods lasting $>6$ days, $\mathrm{p}<0.0001$ ).

Our findings on the prevalence of dysmenorrheal only slightly differ from previous reports on a sample of 2,411 secondary school girls and 107 medical college students $[7,39]$ where the prevalence of dysmenorrhea was $\approx 70 \%$ (6.3\% severe, $30.4 \%$ moderate and $63.3 \%$ mild).

Although dysmenorrhea in adolescent and young adults is usually primary and is associated with normal ovulatory cycles, there is evidence that in approximately 
$10 \%$ of subjects with severe dysmenorrhea, pelvic or uterine anomalies may be found. Endometriosis is a cause of chronic pelvic pain and its presence is suggested by bowel or bladder symptoms or intercourse related pain [5,7].

Our study also showed a significant increase over time in the proportion of girls drinking alcohol, smoking cigarettes, or using oral contraceptives (OC) to prevent pregnancy, whilst their physical activity decreased with age. Similar results have been reported in several Italian reports referring to the same period [45-47]. The significant rising trend in the proportion of adolescent girls who smoke at a younger and younger age, combined with the increasing use of $\mathrm{OC}$ and reduction in physical activity paint a picture that raises a public health concern because it may increase these girls' future morbidity and mortality rates. Health education schemes should be implemented right from kindergarten through $12^{\text {th }}$ grade to reduce health-risk-related behavior [48-51].

Our study has some limitations that need to be addressed. The survey was cross-sectional in design and we could not validate the self-reported information about the girls' menstrual cycles, though the large size of our sample probably sufficed to enable a robust analysis of the menstrual outcomes. Another limitation lies in that no information was obtained on any medical management of dysmenorrhea, though the adolescents reported in the questionnaire whether they took medication for menstrual pain control.

In conclusion, to the best of our knowledge, this is one of the largest studies on menstrual patterns and menstrual disorders among Italian adolescent girls. Our results are consistent with other studies and confirm recent findings on the physiological events involved in the maturation of the female reproductive system.

Adolescents whose menstrual cycles are consistently outside the normal range should be assessed for pathological conditions. No studies have specifically tackled the issue of the duration of the menstrual bleeding period in relation to the menstruation intervals. To the best of our knowledge and literature consultation we found, for the first time, that adolescent girls with oligomenorrhea had longer bleeding periods ( $>6$ days) and this has practical implications because it makes these adolescents potentially more susceptible to iron deficiency anemia.

To sum up, clinicians need to identify menstrual abnormalities as early as possible in order to minimize their possible consequences and sequelae, and to promote proper health information. Health education programs for adolescents remain an important area to develop further for the purposes of prevention.

We recommend that adolescents should be encouraged to chart their menstrual frequency and regularity prospectively from the menarche onwards to focus their attention on the need to take care of their health relating to any menstrual problems.

\section{Competing interests}

The authors have no competing interests to declare.

\section{Authors' contributions}

All authors were involved in the conception and design of the study. EP carried out data extraction and conducted statistical analyses. FR, VDS, SB, $G B, L B, C D S, E P$ drafted the paper with contributions from the co-authors. FR, VDS, EP revised the manuscript. All authors have read and approved the final version of the manuscript.

\section{Acknowledgements}

The authors would like to thank Dr. Leopoldo Ruggiero, Dr. Stefano Ippazio and Dr. Laura Visona` Dalla Pozza for collecting and managing the data for this study.

\section{Author details}

${ }^{1}$ Department of Paediatrics, University of Padua, Padua, Italy. ${ }^{2}$ Private Accredited Hospital Quisisana, Paediatric and Adolescent Outpatients Clinic, Ferrara, Italy. ${ }^{3}$ Department of Clinical and Experimental Medicine, University of Parma, Parma, Italy. ${ }^{4}$ Child and Adolescent Psychiatry Unit, ULSS 16, Padua, Italy. ${ }^{5}$ Division of Paediatrics, Department of Mother and Child Health, Azienda Ospedaliero-Universitaria Maggiore della Carità, Novara, Italy. ${ }^{6}$ Internal Medicine and Therapeutics, Section of Childhood and Adolescence, University of Pavia, Foundation IRCCS San Matteo, Pavia, Italy. ${ }^{7}$ Department of Paediatrics, "Carlo Poma" Hospital, Mantova, Italy. ${ }^{8}$ Department of Paediatrics, Regional Hospital of Bolzano, Bolzano, Italy. ${ }^{9}$ Department of Paediatrics, University of Verona, Verona, Italy. ${ }^{10}$ Department of Paediatrics, Institute for Maternal and Child Health, IRCCS "Burlo Garofolo" and University of Trieste, Trieste, Italy. ${ }^{11}$ Paediatric Department of Paediatrics, Koelliker Hospital, Turin, Italy. ${ }^{12}$ Department of Cardiac, Thoracic and Vascular Sciences, University of Padua, Padua, Italy.

Received: 25 May 2012 Accepted: 31 July 2012

Published: 14 August 2012

\section{References}

1. Tanner JM: Growth at adolescence. 2nd edition. Oxford: Blackwell Scientific; 1962.

2. Karapanou O, Papadimitriou A: Determinants of menarche. Reprod Biol Endocrinol 2010, 8:115.

3. Slap GB: Menstrual disorders in adolescence. Best Pract Res Clin Obstet Gynaecol 2003, 17(1):75-92

4. Flug D, Largo RH, Prader A: Menstrual patterns in adolescent Swiss girls: a longitudinal study. Ann Hum Biol 1984, 11(6):495-508.

5. ACOG Committee on Adolescent Health Care: Menstruation in girls and adolescents using the menstrual cycle as a vital sign. Obstet Gynecol 2006, 108(5):1323-1328.

6. Fraser IS, Critchley HO, Munro MG, Broder M: Can we achieve international agreement on terminologies and definitions used to describe abnormalities of menstrual bleeding? Hum Reprod 2007, 22(3):635-643.

7. Singh A, Kiran D, Singh H, Nel B, Singh P, Tiwari P: Prevalence and severity of dysmenorrhea: a problem related to menstruation, among first and second year female medical students. Indian J Physiol Pharmacol 2008, 52(4):389-397

8. Apter D, Viinikka L, Vihko R: Hormonal pattern of adolescent menstrual cycles. J Clin Endocrinol Metab 1978, 47(5):944-954.

9. Chan SS, Yiu KW, Yuen PM, Sahota DS, Chung TK: Menstrual problems and health-seeking behaviour in Hong Kong Chinese girls. Hong Kong Med J 2009, 15(1):18-23.

10. Treloar AE, Boynton RE, Behn BG, Brown BW: Variation of the human menstrual cycle through reproductive life. Int J Fertil 1967, 12(1 Pt 2):77-126.

11. Vollman RF: The menstrual cycle. Major Probl Obstet Gynecol 1977, 7:1-193.

12. Rigon F, Bianchin L, Bernasconi S, Bona G, Bozzola M, Buzi F, Cicognani A, De Sanctis C, De Sanctis V, Radetti G, Tatò L, Tonini G, Perissinotto E: Update on age at menarche in Italy: toward the leveling off of the secular trend. J Adolesc Health 2010, 46(3):238-244. 
13. Hollingshead AB: Four factor index of social status. New Haven, C: Yale University; 1975. Unpublished manuscript.

14. Petrozza J, Poley K: Dysfunctional uterine bleeding. In Glass's office gynecology. 5th edition. Edited by Curtis MG, Hopkins MP. Baltimore: Williams \& Wilkins; 1999:241-264.

15. Speroff L, Glass RH, Kase NG: Dysfunctional uterine bleeding. In Clinical Gynecologic Endocrinology and Infertility. 5th edition. Baltimore: Williams \& Wilkins; 1994:575-593.

16. World Health Organization: International Statistical Classification of Diseases and Related Health Problems, Tenth Revision. Geneva, Switzerland: World Health Organization; 1992.

17. World Health Organization: Manual of the International Statistical Classification of Diseases, Injuries, and Causes of Death, Ninth Revision. Geneva, Switzerland: World Health Organization; 1977.

18. Wyshak G, Frisch RE: Evidence for a secular trend in age of menarche. $N$ Engl J Med 1982, 306(17):1033-1035.

19. Russo G, Brambilla P, Della Beffa F, Ferrario M, Pitea M, Mastropietro T, Marinello R, Picca M, Nizzoli G, Chiumello G: Early onset of puberty in young girls: an Italian cross-sectional study. J Endocrinol Invest 2011, Epub ahead of print.

20. Metcalf MG, Skidmore DS, Lowry GF, Mackenzie JA: Incidence of ovulation in the years after the menarche. J Endocrinol 1983, 97(2):213-219.

21. World Health Organization (WHO): Multicenter study on menstrual and ovulatory patterns in adolescent girls. II. Longitudinal study of menstrual patterns in the early postmenarcheal period, duration of bleeding episodes and menstrual cycles. World Health Organization Task Force on Adolescent Reproductive Health. J Adolesc Health 1986, 7(4):236-244.

22. Yen SSC: The human menstrual cycle: neuroendocrine regulation. In Reproductive Endocrinology: Physiology, Pathophysiology, and Clinical Management. Edited by Yen SSC, Jaffe RB, Barbieri RL. Philadelphia: W.B. Saunders Co.; 1999:191-217.

23. Wiksten-Almströmer M, Hirscheberg AL, Hagenfeldt K: Menstrual disorders and associated factors among adolescent girls visiting a youth clinic. Acta Obstet Gynecol Scand 2007, 86(1):65-72.

24. Asunción M, Calvo RM, San Millán JL, Sancho J, Avila S, Escobar-Morreale HF: A prospective study of the prevalence of the polycystic ovary syndrome in unselected Caucasian women from Spain. J Clin Endocrinol Metab 2000, 85(7):2434-2438

25. Knochenhauer ES, Key TJ, Kahsar-Miller M, Waggoner W, Boots LR, Azziz R: Prevalence of the polycystic ovary syndrome in unselected black and white women of the southeastern United States: a prospective study. J Clin Endocrinol Metab 1998, 83(9):3078-3082.

26. Diamanti-Kandarakis E: Reproductive endocrinology: Infertility treatment in PCOS-is metformin in from the cold? Nat Rev Endocrinol 2012 8(6):328-330.

27. Hoffman LK, Ehrmann DA: Cardiometabolic features of polycystic ovary syndrome. Nat Clin Pract Endocrinol Metab 2008, 4(4):215-222.

28. Ehrmann DA, Liljenquist DR, Kasza K, Azziz R, Legro RS, Ghazzi MN, PCOS/Troglitazone Study Group: Prevalence and predictors of the metabolic syndrome in women with polycystic ovary syndrome. J Clin Endocrinol Metab 2006, 91(1):48-53.

29. Rotterdam ESHRE/ASRM-Sponsored PCOS Consensus Workshop Group: Revised 2003 consensus on diagnostic criteria and long-term health risks related to polycystic ovary syndrome (PCOS). Hum Reprod 2004, 19(1):41-47

30. Azziz R, Carmina E, Dewailly D, Diamanti-Kandarakis E, Escobar-Morreale HF Futterweit W, Janssen OE, Legro RS, Norman RJ, Taylor AE, Witchel SF, Task Force on the Phenotype of the Polycystic Ovary Syndrome of The Androgen Excess and PCOS Society: The androgen excess and PCOS Society criteria for the polycystic ovary syndrome: the complete task force report. Fertil Steril 2009, 91(2):456-488

31. Ersoy B, Balkan C, Gunay T, Egemen A: The factors affecting the relation between the menarcheal age of mother and daughter. Child Care Health Dev 2005, 31(3):303-308.

32. Papadimitriou A, Gousia E, Pitaouli E, Tapaki G, Philippidis P: Age at menarche in Greek girls. Ann Hum Biol 1999, 26(2):175-177.

33. Gallo PG: The age at menarche in some populations of the Veneto, North Italy. Ann Hum Biol 1977, 4(2):179-181.

34. Malina RM, Bouchard C, Shoup RF, Demirjian A, Lariviere G: Age at menarche, family size, and birth order in athletes at Montreal Olympic Games, 1976. Med Sci Sports 1979, 11(4):354-358.
35. Dewhurst CJ, Cowell CA, Barrie LC: The regularity of early menstrual cycles. J Obstet Gynaecol Br Commonw 1971, 78(12):1093-1095.

36. Widholm O, Kantero RL: A statistical analysis of the menstrual patterns of 8,000 Finnish girls and their mothers. Acta Obstet Gynecol Scand 1971, 14(Suppl 14):1-36

37. Hickey $\mathrm{M}$, Balen $\mathrm{A}$ : Menstrual disorders in adolescence: investigation and management. Hum Reprod Update 2003, 9(5):493-504.

38. Lee LK, Chen PC, Lee KK, Kaur J: Menstruation among adolescent girls in Malaysia: a cross-sectional school survey. Singapore Med J 2006, 47(10):869-874

39. Benjamins LJ, Barratt MS: Evaluation and management of polycystic ovary syndrome. J Pediatr Health Care 2009, 23(5):337-343.

40. Jacot-Guillarmod M, Renteria SC: Menstrual disorders in adolescents: common place or worrisome? Rev Med Suisse 2010, 6:1236-1238. 1240-1.

41. Popat VB, Prodanov T, Calis KA, Nelson LM: The menstrual cycle: a biological marker of general health in adolescents. Ann N Y Acad Sci 2008, 1135:43-51.

42. Beard JL: Iron requirements in adolescent females. J Nutr 2000, 130(2S Suppl):440S-442S

43. Wintrobe MM, Lee GR: Wintrobe's clinical hematology. 10th edition. Baltimore: Williams \& Wilkins; 1999.

44. Guyatt GH, Oxman AD, Ali M, Willan A, Mcllroy W, Patterson C: Laboratory diagnosis of iron-deficiency anemia: an overview. J Gen Intern Med 1992 7(4):145-153.

45. Istituto Nazionale di Statistica: Indagine Multiscopo sulle Famiglie Aspetti della vita Quotidiana Anno 2003. Roma: ISTAT; 2005.

46. Pacifici R, Pichini S, Pizzi E, Zuccaro P: / giovani e il Fumo. Osservatorio Fumo, Alcol e Droga, Istituto Superiore di Sanità: Indagine Doxa; 2003. http://www. ossfad.iss.it, 2003

47. Effective Health Care: Prevenzione dell'abitudine al fumo nei giovani. Edizione Italiana 2000, 4(3):1-12.

48. Donati S, Andreozzi S, Medda E, Grandolfo M: Salute riproduttiva:cosa pensano, quanto sono informati e come si comportano gli adolescenti. Riv Ital Med Adolesc 2004, 3(1):5-12

49. Harris MF, Fanaian M, Jayasinghe UW, Passey M, Lyle D, McKenzie S, Davies GP: What predicts patient-reported GP management of smoking, nutrition, alcohol, physical activity and weight? Aust J Prim Health 2012, $18(2): 123-128$

50. American Academy of Pediatrics, Committee on Substance Abuse: Tobacco, alcohol, and other drugs: the role of the pediatrician in prevention and management of substance abuse. Pediatrics 1998, 101(1 Pt 1):125-128.

51. American College of Obstetricians and Gynecologists Committee on Gynecologic Practice.ACOG Committee Opinion No. 483: Primary and preventive care: periodic assessments. Obstet Gynecol 2011, 117(4):1008-1015.

doi:10.1186/1824-7288-38-38

Cite this article as: Rigon et al:: Menstrual pattern and menstrual disorders among adolescents: an update of the Italian data. Italian Journal of Pediatrics 2012 38:38.

\section{Submit your next manuscript to BioMed Central and take full advantage of:}

- Convenient online submission

- Thorough peer review

- No space constraints or color figure charges

- Immediate publication on acceptance

- Inclusion in PubMed, CAS, Scopus and Google Scholar

- Research which is freely available for redistribution 